\title{
Shoulder to shoulder: stabilising instability, re-establishing rhythm, and rescuing the rotators!
}

\author{
B M Pluim, ${ }^{1}$ R E H van Cingel, ${ }^{2}$ W B Kibler ${ }^{3}$
}

There have been tremendous advances in the diagnosis and management of shoulder injuries. For this issue of the BJSM, we target the world's leading shoulder clinicians to share their insights. We outline the concept of scapular dyskinesis, simplify the classification and management of shoulder instability, and clarify the essentials of office shoulder examination. Are you at all confused as to how to diagnose whether shoulder pain is due to a superior labrum anterior posterior (SLAP) lesion? Do young pitchers with shoulder pain scare you? Then this issue is for you!

\section{KIBLER ON SCAPULAR DYSKINESIS}

Good scapular stability and a normal scapulo-humeral rhythm are essential for good shoulder function. Being able to recognise an abnormal rhythm is the key to managing shoulder injuries. Kibler and Sciascia ${ }^{1}$ identify the causes of an altered scapular resting position and explain the concept of scapular dyskinesis (see page 300). Note the step-by-step guide to the examination of a shoulder with scapular dyskinesis and the recommended treatments.

\section{SIMPLIFYING SHOULDER EXAMINATION}

McFarland et af present a critical review of the various physical examination tests available, and discuss the rationale for and against the use of these tests (see page 328). Moen et a ${ }^{\beta}$ have revisited the metaanalysis of routine shoulder examination tests, carried out by Hegedus et al in the BJSM (See February 2008, page 80), to highlight those that have the greatest sensitivity and specificity (see page 370 ). (For a video of these tests, go to YouTube

${ }^{1}$ Royal Netherlands Lawn Tennis Association, Amersfoort, The Netherlands

${ }^{2}$ Sport Medisch Centrum Papendal, The Netherlands ${ }^{3}$ Lexington Clinic, The Netherlands

\section{Correspondence to}

Dr B M Pluim, Royal Netherlands Lawn Tennis Association, P0 Box 1617, Amersfoort 3800 BP, The Netherlands; bpluim@euronet.nl and type 'Mark Hutchinson shoulder examination,' and you will find them all, perfectly demonstrated.)

\section{MAKING SENSE OF SHOULDER INSTABILITY}

$\mathrm{Kuhn}^{5}$ focuses on the issue of classification to help find a path through the terminology jungle - voluntary, involuntary, TUBS, AMBRI, uni-, bi- and multidirectional, traumatic, atraumatic and microtraumatic (see page 341). He describes a new treatment algorithm based on sound content validity (with reference to frequency, aetiology, direction and severity of instability) (editor's choice). Boone and Arciero ${ }^{7}$ have reviewed the literature on acute first time shoulder instability and challenge the current standard. Despite advances in conservative treatment of shoulder injuries, for first time dislocations, operative treatment is now the treatment of choice in young athletes (see page 355 ).

Jaggi and Lambert ${ }^{7}$ present a comprehensive review of rehabilitation programmes, and you can read a very practical, wellillustrated and evidence-based article on the rehabilitation of the unstable shoulder (see page 333).

\section{UNDERSTANDING SLAP AND BICEPS LESIONS}

Abrams and Safran ${ }^{8}$ review these increasingly common lesions and explain the pathological cascade of posterior inferior capsular tightness and scapular dyskinesis, which cause the 'peel-back' phenomenon at the biceps anchor that leads to a SLAP tear (see page 311). Ejnisman et al's ${ }^{9}$ definitive review of this topic should answer all your outstanding questions (see page 347 ).

\section{AC AND STERNO-CLAVICULAR TRAUMA AND MORE...}

Bontempo and Mazzocca ${ }^{10}$ review these injuries that are common in contact sports (see page 361). AC joint separations account for $40 \%$ of sports-related shoulder injuries. This article will guide your physical and radiographic evaluation, and help you make the difficult treatment decisions associated with a Grade III AC joint separation.

\section{YOUNG ATHLETES}

Leonard and Hutchinson ${ }^{11}$ present an overview of acute and chronic injuries of the shoulder in the growing athlete with particular attention to injuries of the growth plate (see page 306). Practical guidelines to the acceptable number of pitches thrown (and the age at which certain pitches can be attempted) are included to help prevent the development of 'Little Leaguer's Shoulder.'

\section{RESCUING THE ROTATOR CUFF}

Castagna and Garofalo ${ }^{12}$ review the latest literature on internal impingement, a shoulder injury commonly associated with throwing athletes, and discuss the ways in which this entity has evolved over the last decade (see page 382). Thigpen et al $1^{13}$ demonstrate the effect of an exercise intervention to improving shoulder posture and strength in swimmers (see page 371). Finally, we conclude this issue with an article from Ellenbecker and our editorial board member Cools, ${ }^{14}$ who evaluate the treatment of impingement and rotator cuff injuries (see page 319). Follow their advice, and you will be able to cure a SICK scapula and give GIRD the bird!

This issue provides a sound foundation for sports clinicians and may prove to be a springboard for further research into this exciting topic. We thank all the authors for their contribution to this special edition of the BJSM and are delighted with the wide range of papers submitted. Our understanding of this complicated joint has improved enormously in recent years. This demonstrates the benefits of a multidisciplinary approach-a close working relationship between sports physicians, physiotherapists and surgeons can ensure that your athlete rapidly regains full shoulder function, following a complicated shoulder injury. A perfect example of standing shoulder to shoulder!

\section{Competing interests None.}

Provenance and peer review Not commissioned; not externally peer reviewed.

The reference list is published online only at http://bjsm. bmj.com/content/44/5

Accepted 20 February 2010

doi:10.1136/bjsm.2010.072595 


\section{Correction}

An article published in issue 5 of the journal (Pluim BM, van Cingel REH, Kibler WB. Shoulder to shoulder: stabilising instability, re-establishing rhythm, and rescuing the rotators! BrJ Sports Med 2010;44:299) contained an error within the author affiliations list. The affiliation for W B Kibler should be Lexington Clinic Sports Medicine Center, Lexington, KY, USA.

Br J Sports Med 2010;44:578. doi:10.1136/bjsm.2010.072595corr1 